\title{
THE LIFETIME GROWTH AND REPRODUCTION OF SELECTED STRAINS OF MICE
}

\author{
R. C. ROBERTS \\ Agricultural Research Council Unit of Animal Genetics, \\ Institute of Animal Genetics, Edinburgh, 9
}

\section{INTRODUCTION}

Received 30.iii.6r

MosT experiments in quantitative genetics perforce emphasise progress per unit of time, with the resultant quick turnover of generations. Thus, for instance, mouse selection experiments are commonly based on the use of first litters only, where nothing is known of the potential lifetime performance of the animals. Indeed, such information is probably irrelevant from the restricted point of view of a particular study. Yet, it is important to know how experimental procedures with the concomitant changes in genic arrays affect the natural fitness of the organism. In so far as such procedures may disturb gene frequencies in a population at equilibrium, fitness may be expected to decline, on the model of genetic homeostasis proposed by Lerner (1954). It is possible therefore that selection for any character in either direction may lead to a decline in natural fitness. Natural fitness of course has many components whose individual identities must often be obscure. Cumulatively, however, they are perhaps most clearly related to the total reproductive capacity of the organism, measured over the organism's lifetime.

The present study, which is essentially descriptive in nature, comprises a limited examination of these questions. Samples of mouse strains selected for high and low weight were placed aside and allowed to complete their reproductive life. Two main points were examined:

I. The effect of selection for six-week weight on subsequent growth, which may determine or at least affect reproductive capacity.

2. The effect of selection for weight on various aspects of longevity, and particularly on the total number of progeny weaned.

\section{MATERIAL}

Six groups of mice were employed in a comparative study. The designation and derivation of the groups were as follows.

1. RCL, a cross between Goodale's and MacArthur's large mice, and selected further for high six-week weight for Io generations. The origin of the stock is described more fully by Falconer and King (1953).

2. MS, MacArthur's small mice, selected further in this laboratory for low six-week weight for 17 generations.

3. MXR, the $F_{1}$ generation of a cross between $\mathrm{MS}$ and $\mathrm{RCL}$; reciprocal crosses are represented equally in this group. 
4. NF, selected for high six-week weight for 27 generations.

5. NS, selected for low six-week weight for 22 generations.

6. NG, an unselected control stock from the same foundation as NF and NS, kept for 12 generations when this study started.

The last three stocks are described in greater detail by Falconer (1953).

Ten pair matings of each kind were set up and records of weight and litter production were kept. When an animal died, a replacement was provided in order to obtain records from the surviving member of the pair. Death usually resulted from natural causes, although animals were killed if they were in obvious distress and death in any case seemed imminent.

Much of the material, by nature of its erratic reduction until only one animal remained, does not lend itself easily to statistical treatment. Attempts were made to overcome some of the difficulties by the use of various transformations, invariably without much success. Fortunately, however, the main conclusions are often self-evident from the raw data, the presentation of which alone then suffices.

\section{RESULTS}

(i) Length of life

The age at death in days was calculated for all animals. Five mice whose deaths were due to accidental causes have been excluded. The results are shown in table I, with the appropriate analysis of variance in table 2.

TABLE I

Mean age at death in days

\begin{tabular}{|c|c|c|}
\hline Stock & Males & Females \\
\hline $\begin{array}{l}\text { RCL } \\
\text { MS } \\
\text { MXR } \\
\text { NF } \\
\text { NS } \\
\text { NC }\end{array}$ & $\begin{array}{l}474 \cdot 2 \pm 37 \cdot 2 \\
700 \cdot 2 \pm 44 \cdot 1 \\
68 \cdot 1 \pm 66 \cdot 1 \\
759 \cdot 3 \pm 62 \cdot 9 \\
900 \cdot 3 \pm 99 \cdot 4 \\
492 \cdot 7 \pm 78 \cdot 9\end{array}$ & $\begin{array}{l}283 \cdot 8 \pm 29 \cdot 7 \\
45^{2} \cdot 2 \pm 5^{2} \cdot 8 \\
47 \cdot \cdot 4 \pm 60 \cdot 5 \\
730 \cdot 6 \pm 75 \cdot 2 \\
747 \cdot 3 \pm 73 \cdot 0 \\
545^{\cdot} \cdot 1 \pm 80 \cdot 9\end{array}$ \\
\hline
\end{tabular}

TABLE 2

Analysis of variance of mean age at death

\begin{tabular}{|c|c|c|c|c|}
\hline & $d f$ & SS & MS & $p$ \\
\hline Total & I I 4 & 7 190 o69 & & \\
\hline Between sexes & I & 414812 & 414812 & $<0.01$ \\
\hline Between stocks & 5 & 2277620 & 455524 & $<0.001$ \\
\hline Interaction . & 5 & $396 \quad 135$ & 79227 & $>0.05<0.10$ \\
\hline Error. & I03 & 4101502 & 39820 & \\
\hline
\end{tabular}

Among the stocks tested in this trial, there was significant variation between stocks around a mean lifespan of 603 days. Furthermore, under the conditions prevailing in mating cages, males were significantly longer-lived than females, the weighted difference being I 28 days. There is some suggestion that this difference is not constant 
from stock to stock, though the interaction mean square is but barely significant at the ro per cent. level.

Two comparisons enable us to examine the effect on length of life of selection for body weight, that between RCL and MS and that between NF and NS. In both cases, small mice were longerlived though not significantly so in the latter case. Unexpectedly, among the $\mathrm{N}$ stocks selection in either direction increased the lifespan. In the MXR stock, the character displayed considerable heterosis, which is perhaps to be expected. The crossbreds equal almost exactly the longer-lived parental stock. The longest-lived animal in the whole experiment was an NS male, who lived to I 330 days ( 3 years 8 months). Four animals of the NS stock, two males and two females, exceeded I 000 days.

\section{(ii) Patterns of growth}

All animals were weighed when weaned at three weeks, and then at six weeks which is the usual age at mating. Males of the $\mathrm{N}$ stocks were weighed again at nine weeks, and males of all stocks at twelve weeks. Thereafter all males were weighed at four-week intervals until death. After six weeks of age, females were weighed immediately the birth of a litter was recorded, to avoid the obvious variation due to pregnancy. This, however, meant that many females lived over long periods, especially towards the end of their life, without a weight being recorded.

As animals died, the mean weight for each stock became determined by successively smaller numbers as time progressed, until ultimately only one animal remained. For this reason, the results are presented in fig. I as the growth curves of individual male mice. The distribution of growth patterns between stocks is sufficiently distinct, compared to variation within a stock, for the main conclusions to be drawn without any statistical refinements. However, to compensate for any bias in the apparent trends due to a possible correlation between weight and life-span within a stock, cumulative growth curves for males of each stock are shown in fig. 2. These curves were drawn by accumulating the growth of survivors over successive time intervals and are therefore largely independent of the absolute weight of the survivors at the time. The curves in fig. 2 are discontinued when they become determined by fewer than three mice.

We shall not consider the effect of the selection on six-week weight, which is another topic, but rather the consequences of the selection on further growth. Considering initially the weights of males, it is seen that growth was not complete at six weeks, and that the differences between large and small stocks increased rather than diminished, at least for a while. It is at once apparent that selection on total growth up to six weeks has resulted in vastly different mature sizes. Further, inspection of the growth curves shows that even within a stock there 
existed a correlation between six-week weight and maximum weight. Yet, this is not the whole story. A comparison of the two large stocks (RCL and NF) shows that both attained the same mature weight

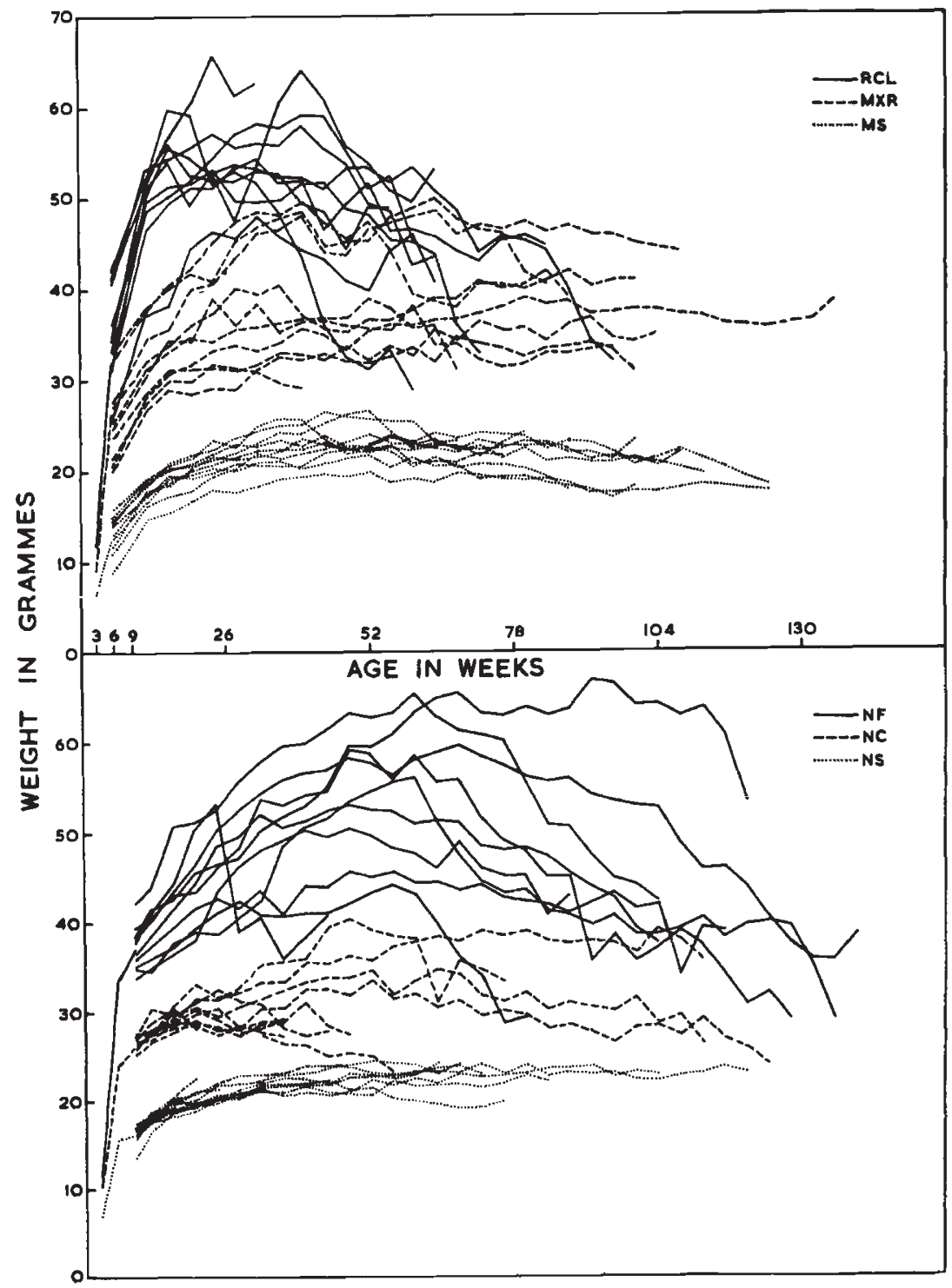

FIG. I.-Individual growth curves of male mice, showing differences in growth pattern between stocks. (Five NS males lived longer than shown, but some of their weights inadvertently were not recorded.)

but at different ages, in the former at approximately six months of age, and in the latter at approximately one year. This is at least presumptive evidence that mature weight and the path whereby it is reached are to some degree under separate genetic control. On this 
point, it can be noted that the RGL males reached their maximum weight at a much younger age than males of other stocks.

Once the maximum weight had been attained, a conspicuous difference in pattern emerged between the two heavy stocks and the others; the former, almost immediately and without exception, began to show a decline in weight which continued without arrest until death. The two light stocks and also the unselected and crossbred stocks, in contrast, showed no decline in weight and retained their

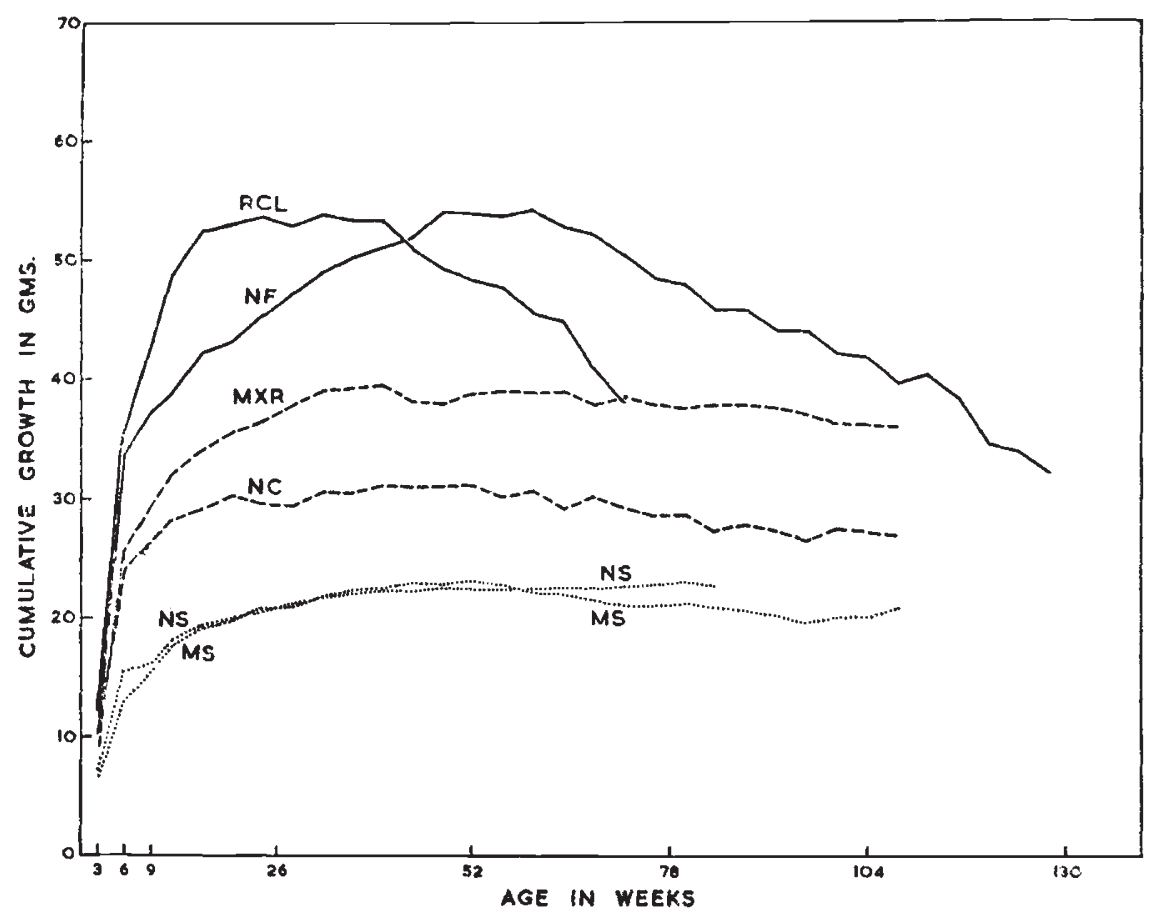

FIG. 2.-Cumulative growth curves of male mice for each stock (explanation in text).

maximum weight almost until death. It seems probable that this difference in weight pattern is related to the difference in fatness; the large mice contain much larger stores of fat, relative to body weight, than small mice (Fowler, I958). The loss of weight of the large stocks in later life was probably due to the depletion of accumulated fat.

The crossbred stock (MXR) showed no evidence of heterosis with respect to mature weight. It did, however, maintain this weight, and it eventually exceeded the level of the heavier parental strain. Whether weight can be regarded as a heterotic character depends therefore on the age at which the character is measured; alternatively, one may argue that the nature of the "character"-in this case, weight-may alter, with age. For instance, it is quite possible that the MXR stock showed heterosis with respect to bodily dimensions at all ages, but failed to accumulate as much fat as the RCL stock. 
The MXR group consisted of an equal number of the two reciprocal crosses. Whereas the group, as a group, was quite distinct from either of the two parental stocks, there was some evidence that within the group mice derived from RCL mothers were heavier than those derived from MS mothers. At maximum weight, the average difference was of the order of five grammes, and the two reciprocal types converged only trivially as they aged, indicating a permanent maternal effect on weight. Though the numbers are quite insufficient to establish this maternal effect as being statistically significant, it is proportionately of the same order of magnitude as that found by Brumby (1960) in analogous groups of mice at twelve weeks of age.

It was explained earlier that the weights of females were somewhat more ambiguously recorded than those of males. In general, however, they provided confirmatory evidence for the conclusions drawn above. All stocks showed that at six weeks, males were appreciably heavier than females. In the two light and two intermediate stocks, however, the ranking of the sexes almost immediately became reversed. This could easily be attributed to a peculiarity of the post-partum weight recorded in females, were it not for the fact that the two heavy stocks did not exhibit the same phenomenon. A possible explanation might be that breeding females of the RCL and NF stocks did not accumulate the same amount of fat as males of those stocks.

\section{(iii) Reproductive performance}

The data referring to the reproductive history of the stocks are summarised in tables 3 and 4 , which refer to females only. The first point, not revealed in the tables, is that stocks did not differ significantly in the age at which the first litter was born. This would almost certainly not have been the case had not mating been delayed for all stocks until they were on average about eight weeks old. Having thus begun on an equal footing, four major factors govern the reproductive capacity of the stocks - the length of breeding life, the interval between litters, the average size of the litters at birth and the proportion of those born that survive to be weaned.

It is seen that the female mice in this trial stopped breeding at an average age of 300 days or so, but the variation among stocks is highly significant. Reproduction ceased at a younger age in the large stocks than in the small stocks. Further, referring back to table I, some stocks, notably the NF, lived for a considerable time after reproduction had ceased. The correlation between the age at last litter and female longevity, with respect to stock means, is less than 0.5 , despite an obvious causal relationship. However, this estimate, based on only six stocks, cannot be very accurate. Neither of the large stocks produced litters beyond the point when they would be expected to show the decline in weight characteristic of males of those stocks. Unfortunately, for reasons explained earlier, no weights 
were obtained from females in later life to determine whether in fact they did lose weight.

The conclusions with respect to the age at which the last litter was born are clear. Firstly, selection for large size decreased the length of reproductive life while selection for small size increased it.

TABLE 3

Lifetime reproduction of females-numbers born alive

\begin{tabular}{|c|c|c|c|c|c|}
\hline Stock & $\begin{array}{l}\text { Mean age } \\
\text { (in days) } \\
\text { at last litter }\end{array}$ & $\begin{array}{l}\text { Mean no. } \\
\text { of litters }\end{array}$ & $\begin{array}{c}\text { Mean interval } \\
\text { (in days) } \\
\text { between } \\
\text { litters } *\end{array}$ & $\begin{array}{c}\text { Mean total } \\
\text { no. born }\end{array}$ & $\begin{array}{l}\text { Mean } \\
\text { litter size } \\
\text { at birth } \dagger\end{array}$ \\
\hline $\begin{array}{l}\text { RCL } \\
\text { MS } \\
\text { MXR } \\
\text { NF } \\
\text { NS } \\
\text { NC }\end{array}$ & $\begin{array}{l}201 \cdot 2 \pm 30 \cdot 9 \\
295 \cdot 8 \pm 51 \cdot 2 \\
377 \cdot 6 \pm 43 \cdot 3 \\
238 \cdot 4 \pm 28 \cdot 9 \\
428 \cdot 0 \pm 44 \cdot 7 \\
307 \cdot 2 \pm 27 \cdot 1\end{array}$ & 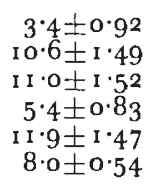 & $\begin{array}{l}42 \cdot 65 \\
22 \cdot 74 \\
29 \cdot 36 \\
34 \cdot 44 \\
30 \cdot 92 \\
32 \cdot 00\end{array}$ & $\begin{array}{r}24.2 \pm 6.77 \\
49.0 \pm 7.37 \\
\text { I02.5 I0.35 } \\
33.0 \pm 5.77 \\
48.8 \pm 6.65 \\
44.8 \pm 5.57\end{array}$ & $\begin{array}{l}7 \cdot 1 \\
4 \cdot 6 \\
9 \cdot 3 \\
6 \cdot 1 \\
4 \cdot 1 \\
5 \cdot 6\end{array}$ \\
\hline
\end{tabular}

* Mean age at last litter-Mean age at mating

Mean no. of litters

$\uparrow$ Mean total no. born

Mean no. of litters

TABLE 4

Lifetime reproduction of females--numbers and weight of offspring weaned

\begin{tabular}{|c|c|c|c|c|c|}
\hline Stock & $\begin{array}{l}\text { Mean total } \\
\text { no. weaned }\end{array}$ & $\begin{array}{c}\text { Proportion } \\
\text { weaned }\end{array}$ & $\begin{array}{c}\text { Mean total } \\
\text { wt. (in gm.) } \\
\text { of offspring } \\
\text { weaned }\end{array}$ & $\begin{array}{c}\text { Mean total } \\
\text { wt. (in gm.) } \\
\text { weaned by } \\
\text { I } 83 \text { days }\end{array}$ & $\begin{array}{l}\text { Proportion of } \\
\text { total wt. } \\
\text { weaned by } \\
\text { I } 8_{3} \text { days }\end{array}$ \\
\hline $\begin{array}{l}\text { RCL } \\
\text { MS } \\
\text { MXR } \\
\text { NF } \\
\text { NS } \\
\text { NC }\end{array}$ & $\begin{array}{l}\text { I } 8 \cdot 6 \pm 5 \cdot 70 \\
31 \cdot 1 \pm 6 \cdot 30 \\
93 \cdot 4 \pm 9 \cdot 27 \\
18.8 \pm 4.57 \\
37.5 \pm 7 \cdot 98 \\
33.4 \pm 5 \cdot 16\end{array}$ & $\begin{array}{l}0.77 \pm 0.027 \\
0.63 \pm 0.022 \\
0.91 \pm 0.009 \\
0.57 \pm 0.027 \\
0.77 \pm 0.018 \\
0.75 \pm 0.020\end{array}$ & $\begin{array}{l}198 \cdot 99 \pm 56 \cdot 13 \\
205.70 \pm 41 \cdot 85 \\
847 \cdot 24 \pm 106 \cdot 14 \\
176.54 \pm 36.57 \\
265.45 \pm 53.89 \\
298.31 \pm 48.75\end{array}$ & 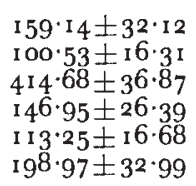 & $\begin{array}{l}0.80 \\
0.49 \\
0.49 \\
0.83 \\
0.43 \\
0.67\end{array}$ \\
\hline
\end{tabular}

Secondly, reproductive longevity, as illustrated by the MXR stock, displays striking heterosis.

The length of reproductive life is reflected, to a large extent in the mean number of litters born to females of particular stocks. It is seen that the large stocks do not compensate for their shorter reproductive life by a more rapid litter production. On the contrary, the disparity between the large and the small stocks is magnified rather than diminished. However, the large stocks make up some leeway by producing larger litters, few though they may be. But the advantage of the small stocks in the number of litters born is a telling 
one, and their superiority over the large stocks in the total number of offspring born is in no doubt.

The fitness of an animal depends of course not so much on the number of progeny to which it gives birth as on the number of those progeny that reach sexual maturity and themselves reproduce. However, it is common experience that relatively few losses occur in the laboratory mouse after weaning, and that sterility also is comparatively rare. The total number of offspring weaned therefore provides some assessment, though by no means an exact one, of the reproductive fitness of a mouse. When the appropriate column in table 4 is examined, the small stocks are seen to have retained their advantage in the total number of offspring by weaning time. It is further seen that this is mostly due to the initial advantage in number born, and that the variation in the proportion of offspring that survive to weaning is not correlated with large and small size. Perhaps the most impressive feature of the data is the striking heterosis displayed by the MXR stock, which weaned three times as many young as the better of its two parental stocks. The crossbred animals were very successful in all aspects of reproduction, and outstandingly so in the mean litter size at birth and in rearing those litters to weaning.

The pattern of reproduction in the mouse is well-known. The first litter on average is submaximal owing to fewer ova being shed. Litter size then remains at a fairly stable maximal level over three parities or more, but eventually it gradually declines. The decline is reported to be due at least in part to an increased incidence of foetal mortality (Hollander and Strong, 1950; Wanke, 1939; Murray, 1934). The mean litter sizes at birth of successive parities for each stock are shown in fig. 3. The graphs, which are discontinued when they become determined by fewer than four mice, all conform to the expected pattern. There is some variation in the parity at which the maximum litter size is achieved which, however, does not seem to be correlated with body size. The crossbred stock (MXR), despite retaining its superiority in mean number born over twelve litters, does ultimately fall to the level of the small stocks; in fact, its decline with advancing age is the most marked. Nevertheless, it appears that the onset of senescence, as judged by the decline in litter size with age, is somewhat delayed in the crossbred stock, a finding which fails to support a suggestion by Chai (I959) that hybridisation confers no such effect.

The general conclusion with regard to the reproduction of the stocks tested in this trial is that mice selected for small size have a far higher reproductive rate than mice selected for large size, and possibly a higher rate than the unselected control mice. It has further been shown that the advantage of small mice rests entirely on the number of litters that they produce, which in turn can be related to the length of reproductive life. The one crossbred stock tested displayed the expected heterosis in reproductive capacity. 
(iv) Total weight of offspring weaned

Those concerned with the applied aspects of this study may legitimately ask whether the number of offspring weaned is as important as the total weight of those offspring, especially the total weight within a given time from mating. This is primarily an economic question for which there is no general answer, but the data collected in this study are presented in table 4 . It is seen that the advantage

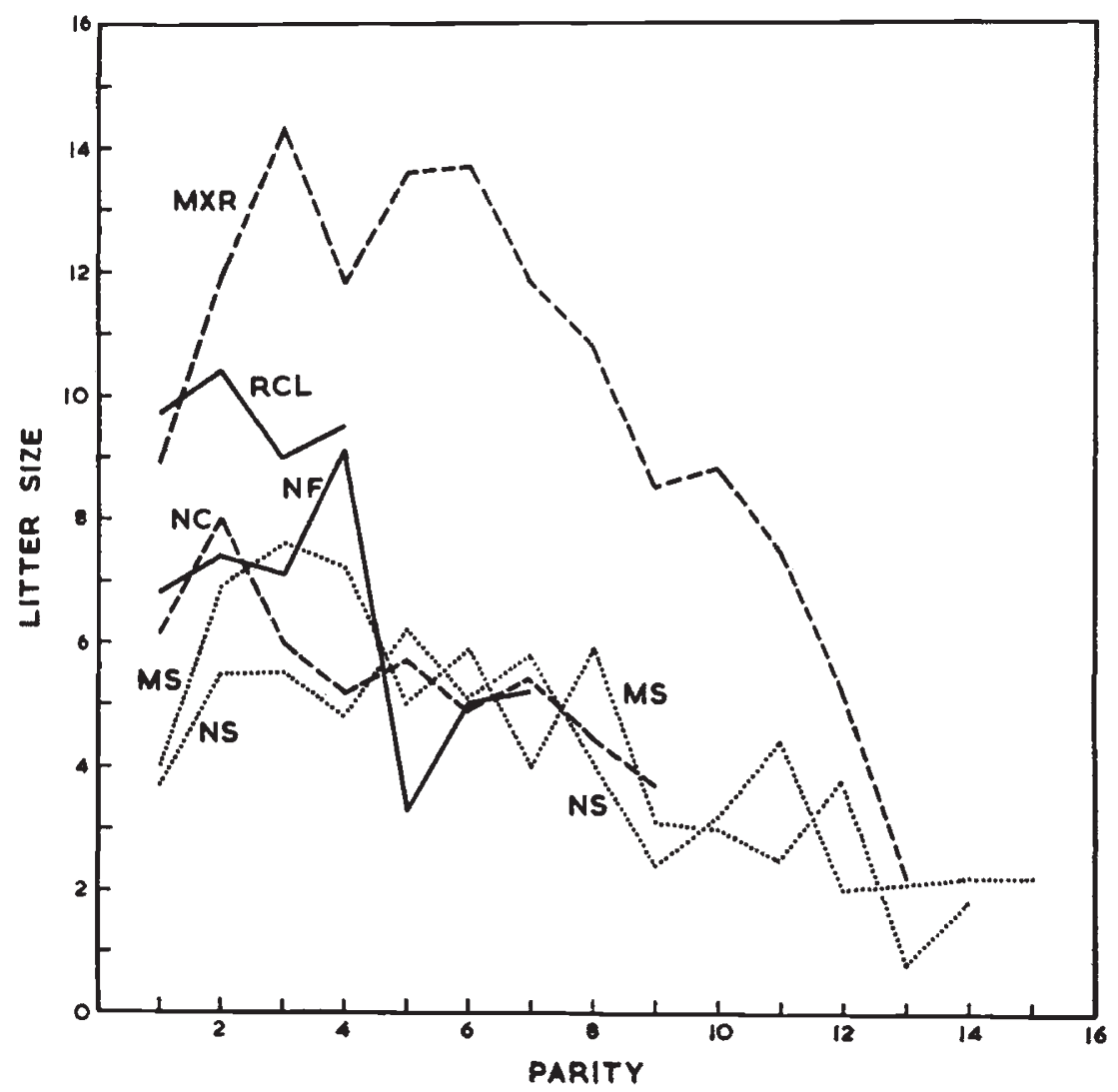

FIG. 3.-The relationship between litter size at birth and parity, for each stock.

of the small stocks in the total number weaned is sufficient to give them a superiority also in the total weight of these offspring at weaning. However, in neither of the two comparisons between large and small stocks is the difference statistically significant; in fact, the superiority of the MS stock over the RCL is quite trivial. Furthermore, as shown previously, the small stocks took a considerably longer time to accumulate those weights. For this reason, the cumulative weaning weights up to the age of 183 days $(6$ months) were examined. This period was chosen because by then all stocks are past their peak reproductive capacity, and are therefore at a stage when matings would be terminated under normal mouse management. The 
appropriate column in table 4 shows the large stocks in a more favourable light. At this age, they exceed the performance of the small stocks, though not significantly. The conclusion is that if interest rests on the weight of offspring per female parent, stocks selected for high body weight are probably preferable to stocks selected for small size, which ultimately give more litters but these are smaller and contain lighter mice. A firmer conclusion would invoke economic considerations which are beyond the scope of this paper.

Two final points from table 4 should be mentioned. Firstly, the performance of the crossbred stock (MXR) is again outstandingly high. Secondly, among the $\mathrm{N}$ stocks, selection for six-week weight in either direction has resulted in a decrease of the total weight of offspring weaned, compared to the unselected control stock. The immediate reason for this is not hard to find. In the small stock the decrease is directly attributable to a reduction in weight as a result of the selection, while the decrease in the large stock results from the marked reduction in the number of offspring weaned.

\section{DISCUSSION}

None of the characters described in this paper had been the subject of previous artificial selection in these stocks of mice. The differences found between large and small stocks can therefore be classified as correlated responses to selection for six-week weight. A detailed discussion of the theory of correlated responses would be inappropriate here; a recent exposition is given by Falconer (I960). Briefly, however, a correlated response to selection cannot arise in the absence of a genetic correlation between the two characters, though other factors will also contribute to the magnitude of the response. A genetic correlation implies either that some genes affect both characters, i.e. are pleiotropic, or that genes affecting the characters separately are linked predominantly in the one phase. Whereas in the selected lines, it might be expected that equilibrium would have been reached between the coupling and repulsion phases, it might well be that genetic correlations as a result of linkage would be important in the crossbred stock examined in this study.

Selection on total growth up to six weeks has been shown in the previous section to have affected a number of other characters as well. Not surprisingly, perhaps, it has had a marked effect on subsequent growth and has led to different maximum weights, though the proportional differences between the large and small stocks are substantially the same at six weeks and at mature weight. From this alone, it would not be unreasonable to argue that the same genetic system controls both six-week and mature weights. But the different growth pattern of the two large stocks clearly suggests at least some genetic independence between growth rate and mature weight, and 
thus shows broad agreement with the hypothesis of mammalian growth proposed by Dickinson (1960).

Selection for body weight had a marked effect on length of life and particularly on the length of reproductive life. The reason for this is obscure, but a possible parallel may be drawn from nutritional studies by McCay (1947), Ball et al. (1947) and Visscher et al. (1952). Briefly, these studies cumulatively show from work with rodents that the restriction of calorie intake through the diet lengthens life and also delays the age of reproductive failure, as judged by the capacity of the females to produce litters. Now, the parallel is pertinent only if the small stocks in this study can be regarded as a biological means of restricting calorie intake. For instance, small mice may utilise a relatively greater portion of their calorie intake to maintain body temperature. If so, then the direct cause of the differences found in length of reproductive life becomes a mechanical one resulting from differences in body size, though the complexities at the physiological level remain.

The finding concerning the relative longevity of large and small stocks is not in accord with that of Chai (1959), whose large strain significantly outlived his small strain. His material, however, was inbred, and is therefore not directly comparable with the present study. Chai found too that a hybrid stock derived from a cross between his large and small strains had a lifespan in excess of either parental strain.

The correlated responses to selection found in this trial were usually in opposite directions in the large and small stocks. On a homeostatic model, discussed earlier, this is not the expectation for characters related to fitness. The general finding suggests therefore that in the material examined here, genetic homeostasis was not a predominating feature of the base populations. There were only two instances in which the correlated responses assumed the same direction in both large and small mice, the comparisons being of course limited to the $\mathrm{N}$ stocks which contained a control. Firstly, the mean age at death increased in both selected stocks. The reason for this is obscure. It should, however, be noted that the age at which reproduction ceased, a more direct component of fitness, responded differently in large and small mice. Secondly, the total weight of offspring weaned declined in both selected lines for reasons given earlier. While this character is almost certainly related to some aspects of fitness, it is less obviously so than the total number weaned, where the correlated responses were in opposite directions.

The final conclusion from this study is that selection for a rapid early growth had an adverse effect on reproductive fitness, as judged by the total number of offspring weaned over a lifetime. This reduction in number of offspring resulted mainly from a drastic shortening of the length of reproductive life. Given time, mice selected in the opposite direction showed no reduction in number weaned, though of 
course the total weight of offspring was reduced. In terms of practical application to domestic livestock, a good growth rate and high reproductive capacity are frequently twin objectives. The general conclusion is therefore discouraging. However, depending upon economic and biological considerations, the consequences of a shortened reproductive life in some species may not be serious. Further, the apparent negative correlation between growth rate and reproductive capacity may not be so great that its effect could not be overcome or at least diminished by appropriate selection techniques. And lastly, this study confirms that the crossing of suitably selected strains may offer a solution to what might otherwise become stagnating fertility problems.

\section{SUMMARY}

I. This paper reports the effect of selection for six-week weight in mice on their subsequent growth and on various aspects of their longevity, particularly on the length of reproductive life.

2. The material consisted of ten pair matings each of two large strains, two small strains, a large $\times$ small cross and an unselected control strain.

3. The average length of life over all stocks was I year 8 months. The mean life span of the small strains exceeded that of the large strains by approximately 6 months, while the crossbred stock equalled almost exactly the better parental strain.

4. The difference in weight between the large and small strains magnified with age though the proportionate difference remained fairly stable. However, the two large strains, once their maximum weight had been achieved, showed a decline in weight which continued until ultimately they fell to the level of the intermediate strains. The cause of the decline, which was not a feature of the other four groups, was probably the depletion of fat reserves.

5. The large strains had a short reproductive life, producing on average only $4 \frac{1}{2}$ litters, against I I or so in the small strains. On account of this the small strains eventually weaned almost twice as many offspring as the large strains.

6. Perhaps the most striking feature of the data was the heterosis displayed by the crossbred stock with respect to reproductive capacity. Compared to the better parental strain, the crossbred stock weaned three times as many offspring whose total weaning weight was four times as great.

7. The findings are discussed in relation to the original selection for high and low six-week weight.

Acknowledgments. - I am greatly indebted to Dr D. S. Falconer for making available records which made this study possible; he collected the records from mice providing for other requirements. I wish to thank him also for his valuable comments on the manuscript.

I wish to thank Mr E. D. Roberts for drawing the figures; I appreciate his patience with the cumbersome fig. I. 


\section{REFERENCES}

BALL, z. B., BARNES, R. H., AND visscher, M. B. 1947. The effects of dietary calorie restriction on maturity and senescence, with particular reference to fertility and longevity. Amer. 7. Physiol., I50, 511-519.

BRUMBY, P. J. 196o. The influence of the maternal environment on growth in mice. Heredity, I4, I-18.

ChaI, c. K. 1959. Life span in inbred and hybrid mice. 7. Hered., 50, 203-208.

DICKINSON, A. G. 1960. Some genetic implications of maternal effects-an hypothesis of mammalian growth. 7. Agric. Sci., 54, 378-390.

FALCONER, D. S. 1953. Selection for large and small size in mice. 7. Genet., $5 I$, 470-501.

FALCONER, D. S. 1960. Introduction to Quantitative Genetics. Oliver and Boyd, Edinburgh.

FALCONER, D. s., AND KING, J. W. B. 1953. A study of selection limits in the mouse. 7. Genet., 5I, 561-58I.

FOWLER, R. E. 1958. The growth and carcass composition of strains of mice selected for large and small body size. 7. Agric. Sci., 5I, 137-148.

HOLLANDER, W. F., AND STRONG, L. C. 1950. Intra-uterine mortality and placental fusions in the mouse. 7. exp. Zool., II5, 131-149.

LERner, I. M. 1954. Genetic Homoestasis. Oliver and Boyd, Edinburgh.

McCAY, C. M. 1947. Effects of restricted feeding upon aging and chronic diseases in rats and dogs. Amer. 7. Publ. Hlth., 37, 521-528.

MURRAY, w. s. 1934. The breeding behaviour of the dilute brown stock of mice (Little dba). Amer. 7. Cancer, 20, 573-593.

VISSCHER, M. B., KING, J. T., AND LEE, C. P. I952. Further studies on influence of age and diet upon reproductive senescence in strain A female mice. Amer. 7. Physiol., $170,72-76$.

WANkE, s. 1939. Einfluss der Wurfreihenfolge auf die Wurfgröse sowie der Wurfgrösse und der Wurfreihenfolge auf die Sterblichkeit von weissen Mäusen während der Saugezeit. Z. Tierz. ZüchtBiol., 42, 269-280. 